\title{
COMPUTATIONAL STUDIES OF PURINE DERIVATIVE USING MULTIFORMS OF HUMAN POLYPEPTIDES 1 AS TARGET ENZYME FOR ANTICANCER AGENTS
}

\author{
MARINA JULIET A ${ }^{1}$, HEMALATHA CN ${ }^{1,2}$, VIJEY AANANDHI ${ }^{1 *}$ \\ ${ }^{1}$ Department of Pharmaceutical Chemistry, School of Pharmaceutical Sciences, Vels University (VISTAS), Chennai, Tamil Nadu, India. \\ ${ }^{2}$ Research Scholar, School of Pharmaceutical Sciences, Vels University (VISTAS), Chennai, Tamil Nadu, India. \\ Email: hodpchemistry@velsuniv.ac.in
}

Received: 22 April 2017, Revised and Accepted: 31 May 2017

ABSTRACT

Objective: This research was conducted to prove and estimate the activity of the newly designed compound by applying quantitative structure-activity relationship (QSAR) study using Vlife molecular design suite (MDS) 2 software on various purine derivatives. These novels scaffolds/candidates, which could have the potential to inhibit 5FSO would represent promising starting points as lead compounds and certainly aid the experimental designing of anticancer drugs.

Materials and Methods: Purine derivatives are studied and based on the QSAR study new structures are drawn and predicted the biological activity using the Vlife MDS Software-Module Name: QSAR Plus. Auto dock 1.2.6 software is a suite of automated docking tools. It is designed to predict how small molecules, such a substrate or drug candidates, bind to receptors of the known 3D structure. 5FSO protein preparation and optimization, ligand preparation and optimization, and docking simulations were carried out by using biological databases such as PubChem, Drug Bank, Protein Data Bank.

Results: To estimate the activity, computational studies had been applied. In addition, the newly designed compound can be used as a scaffold to design more purine compounds which may be a potent inhibitor of 5FSO protein.

Conclusion: The results depict as the newly designed molecules has better binding energy than standard drug and these compounds may possess better anticancer activity.

Keywords: Anticancer, Purine derivative, Multiforms of human polypeptides 1, NUDT 1, Quantitative structure-activity relationship.

(C) 2017 The Authors. Published by Innovare Academic Sciences Pvt Ltd. This is an open access article under the CC BY license (http://creativecommons. org/licenses/by/4. 0/) DOI: http://dx.doi.org/10.22159/ajpcr.2017.v10i9.19340

\section{INTRODUCTION}

Antineoplastic or anticancer drugs are the drug that prevents or inhibit the maturation and proliferation of neoplasms. Antineoplastic agent travels the body and destroys cancer cells. Anticancer drugs are concerned with clinical and experimental effects of toxic and nontoxic cancer agent and are specifically directed toward a breakthrough in cancer treatment. Purine is a heterocyclic, aromatic, and organic compound, consisting of a pyrimidine ring fused to an imidazole ring. Purines, including substituted purines and their tautomers, are the most widely distributed kind of nitrogen-containing heterocyclic compounds present in nature [1]. Prominent purines (derivatives) include caffeine, and two of the bases in nucleic acids are adenine and guanine. In DNA, adenine and guanine form hydrogen bonds with their complementary pyrimidines, thymine, and cytosine. In RNA, the complement of adenine is uracil instead of thymine. Purine is also a component in adenosine triphosphate, which stores and transports chemical energy within the cells [2].

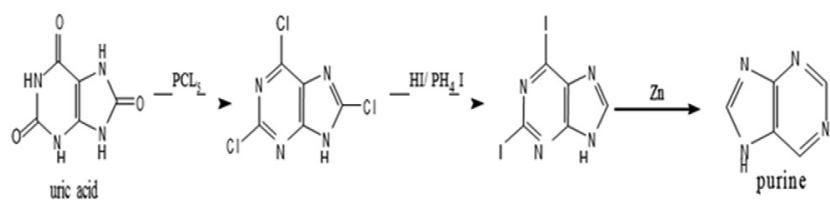

Multiforms of human polypeptides 1 (MTH1) is to overcome the incorporation of oxidized nucleotides into DNA, which otherwise can result in mispairing, mutations, and cell death. The inhibitors were found to be less toxic to several primary or immortalized cells. MTH1 being required for cancer cell survival while being non-essential in untransformed cells [3]. Toll-like receptor (TLR7) is a ligand or an ion or molecule (functional group) that binds to a central metal atom to form a coordination complex. The bonding between metal and ligand generally involves the formal donation of one or more of the ligand's electron pairs.

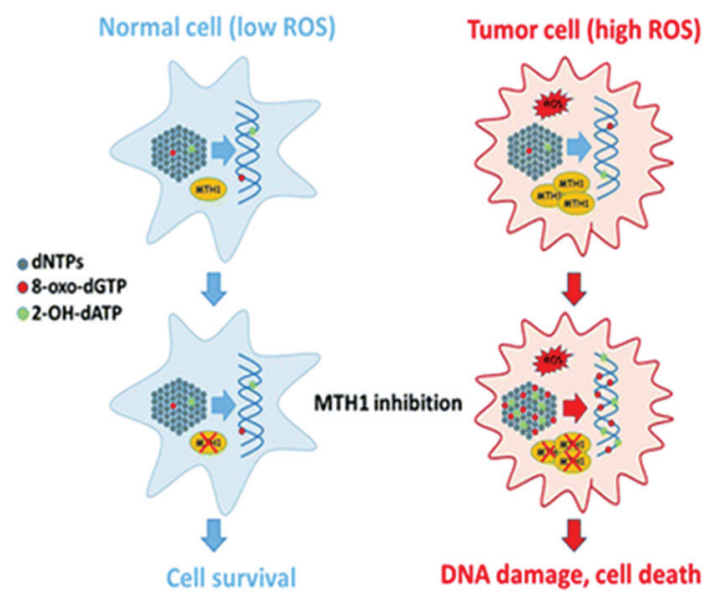

\section{MATERIALS AND METHODS}

Material

Quantitative structure-activity relationship models (QSAR models) are regression or classification models used in the chemical and biological sciences and engineering. Such as other regression models, QSAR 
Table 1: Newly designed 15 compounds with biological activity

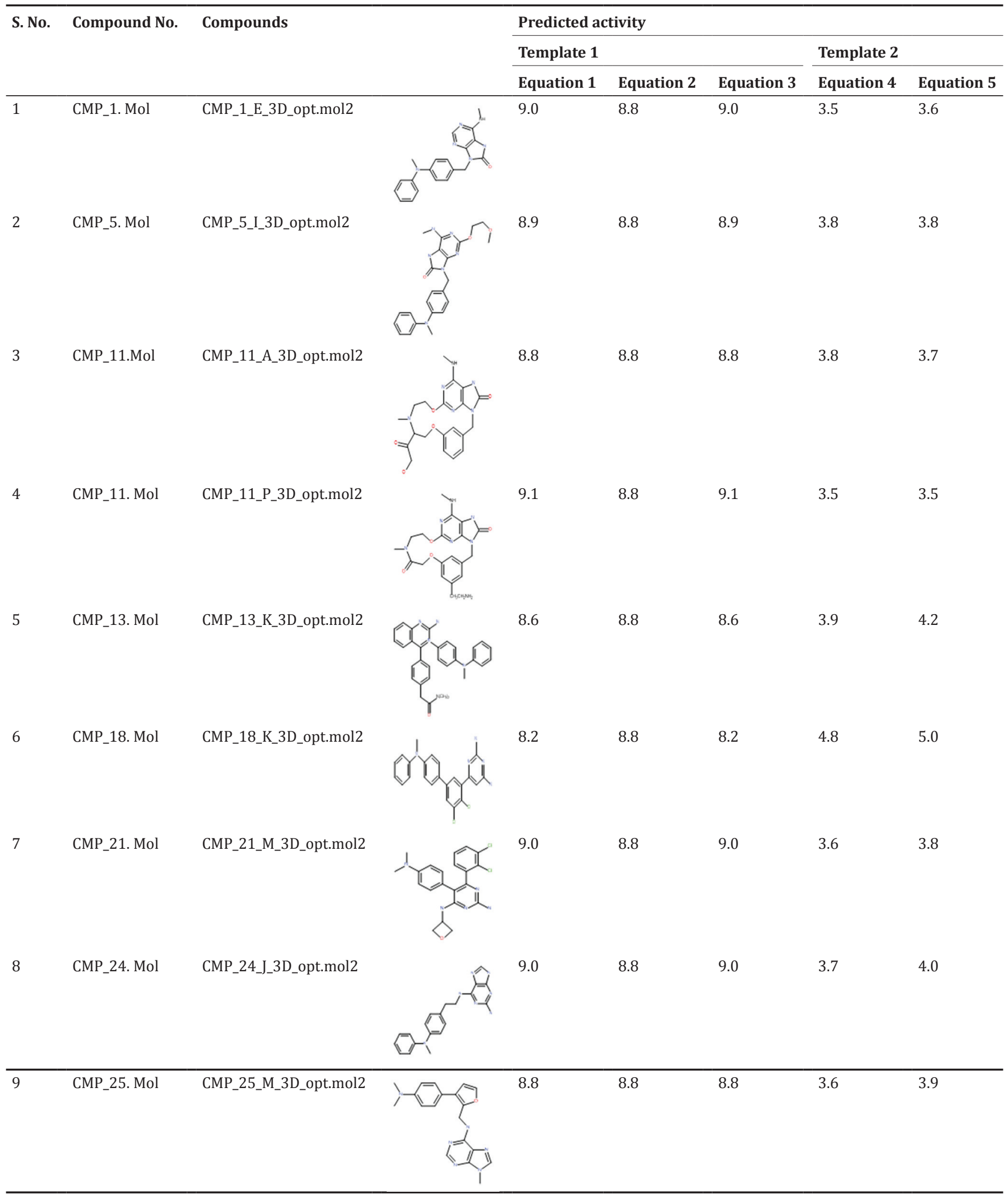

(Contd...) 
Table 1: (Continued)

\begin{tabular}{|c|c|c|c|c|c|c|c|}
\hline \multirow[t]{2}{*}{ S. No. } & \multirow[t]{2}{*}{ Compound No. } & \multirow[t]{2}{*}{ Compounds } & \multicolumn{3}{|l|}{ Template 1} & \multicolumn{2}{|l|}{ Template 2} \\
\hline & & & Equation 1 & Equation 2 & Equation 3 & Equation 4 & Equation 5 \\
\hline 10 & CMP_30. Mol & CMP_30_K_3D_opt.mol2 & 8.4 & 8.8 & 8.4 & 3.5 & 3.8 \\
\hline 11 & CMP_30. Mol & CMP_30_N_3D_opt.mol2 & 8.4 & 8.8 & 8.4 & 3.5 & 3.7 \\
\hline 12 & CMP_31. Mol & CMP_31_J_3D_opt.mol2 & 9.0 & 8.8 & 9.0 & 3.5 & 3.7 \\
\hline 13 & CMP_6. Mol & CMP_6_D_3D_opt.mol2 & 8.7 & 8.8 & 8.8 & 3.5 & 3.5 \\
\hline 14 & CMP_8. Mol & CMP_8_D_3D_opt.mol2 & 8.8 & 8.8 & 8.8 & 3.5 & 3.5 \\
\hline 15 & CMP_9. Mol & CMP_9_D_3D_opt.mol2 & 8.8 & 8.8 & 8.8 & 3.5 & 3.5 \\
\hline
\end{tabular}

Table 2: Molecular docking analysis

\begin{tabular}{lllllcc}
\hline Drug & $\boldsymbol{\Delta G}(\mathrm{kcal} / \mathrm{Mol})$ & $\mathrm{KI}(\mathbf{M m})$ & $\begin{array}{l}\text { Internal } \\
\text { energy }\end{array}$ & vdWhbdesolv_energy & $\begin{array}{l}\text { Electrostatic } \\
\text { energy }\end{array}$ & Total internal \\
\hline CMP_11_A & -0.11 & 3.71 & -6.14 & -5.84 & -0.31 & -0.46 \\
CMP_18_K & -0.1 & 6.31 & -3.47 & -3.38 & -0.09 & -0.63 \\
CMP_21_M & -0.09 & 13.95 & -3.12 & -2.95 & -0.17 & -0.78 \\
CMP_24_J & -0.02 & 41.7 & -4.66 & -4.62 & -0.04 & -0.51 \\
6Mercaptopurine & -0.29 & 7.17 & -2.93 & -2.86 & 0.06 & 0.0 \\
\hline
\end{tabular}

regression models relate a set of "predictor" variables $(\mathrm{X})$ to the potency of the response variable (Y), while classification QSAR models relate the predictor variables to a categorical value of the response variable. Literature surveys of some purine derivatives are studied and based on the QSAR Study new structures are drawn and predicted the biological activity using the Vlife molecular design suite (MDS) Software-Module Name: QSAR plus.

In the field of molecular modeling, docking is a method which predicts the preferred orientation of one molecule to a second when bound to each other to form a stable complex. Knowledge of the preferred orientation, in turn, may be used to predict the strength of association or binding affinity between two molecules. Auto dock 1.2.6 software is a suite of automated docking tools. It is designed to predict how small molecules, such a substrate or drug candidates, bind to receptors of the known 3D structure.

\section{RESULTS AND DISCUSSIONS}

In this of purine derivatives are chosen to estimate the activity of various derivatives, which will increase anticancer activity using 5FSO protein. To estimate the activity, two studies had been applied. First one was QSAR studies to the structure activity relationship and activity of various purine derivatives. QSAR studies have done and by changing various descriptors the best activity was obtained by the sphere exclusion method. Finally, from QSAR 15 compounds are showing good 
Table 3: Graphical representation of compounds with respect to the templates

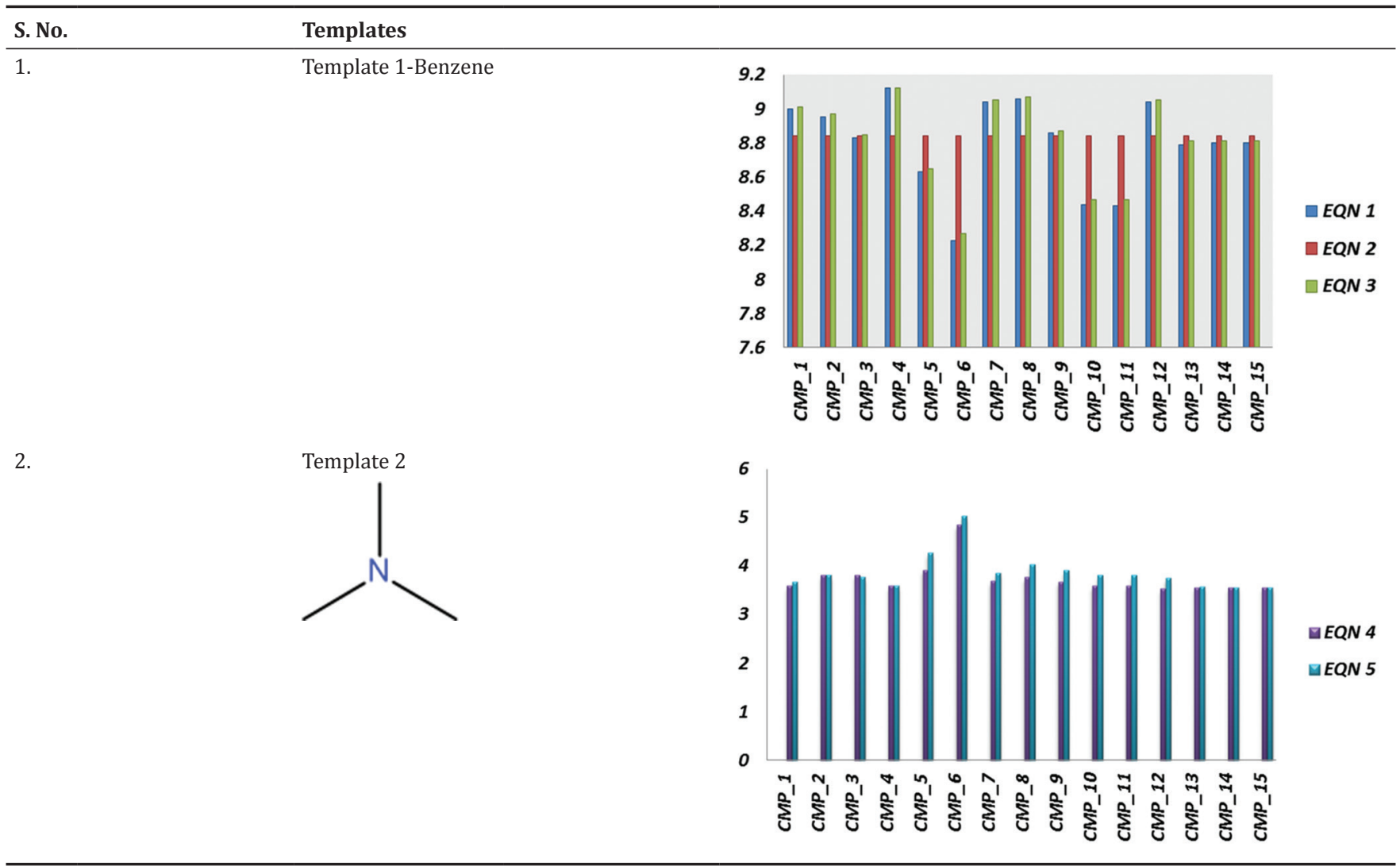

activity. These final results are tabulated in Table 1. These compounds are screened using 5FSO proteins and docking studies were carried out. Among the 15 compounds, the 4 compounds possess good activity for 5FSO protein and these 4 compounds show best dock scores and this compound may possess further invite has been studied and they will increase the anticancer activity. These results are tabulated in Table 2. From this, CMP_21_M shows a best-docked score and good binding energy is tabulated in Fig. 1.

The new compounds were designed on the basis of standard 32 compound descriptors were calculated in QSAR Module that is S_814, E_525, and E_707. Electropositive and steric groups and the carboxyl acid esters are used to design new compounds.

Glutamic acid plays an important role in the biosynthesis of purine and pyrimidine bases of DNA and RNA. It is metabolized to L-glutamine by L-glutamine synthetase and this metabolic process is essential for normal maintenance of cells. The synthesis of L-glutamine is hindered in neoplastic cells due to lower reactivity of L-glutamine synthetase. Thus, antagonists of this enzyme can interfere with the metabolic role of L-glutamine and act as anticancer agents [4]. For this purine, compound is taken for docking and it also has a possibility to synthesize new compounds easily.

Descriptors of ligands, receptors, and their cross terms were correlated to ligand-receptor interaction affinity using sphere exclusion. Several models were created, using descriptors of compounds formed from different combinations [5].

The ligand receptor also shows a distance in hydrogen atoms. There is still a long way to a proper understanding of agonist-induced receptor activation. It is also beside traditional methods of molecular pharmacology, computational work will play an important role in clarifying this process. Multiscale treatment of the receptor activation process is a method of choice. The methodology, has to a certain extent been developed [6-9] and will lead toward a greater understanding of receptor activation and the design of new drugs.

The structure of newly designed 15 compounds shows good biological activities are tabulated in Table 1.

Selected 15 compounds biological predicted activities are plotted as a graph are tabulated in Table 3.

The Ramachandran plot, residue properties, etc., are generated by procheck server Fig. 1.

\section{CONCLUSIONS}

In this study, QSAR was chosen for a structure-activity relationship, predicted the biological activity and the selected best compounds are chosen for docking study by taking 5FSO protein. Docking has been carried out in Auto dock and the binding affinities of protein with the drug are carried out.

The QSAR study was done in Vlife MDS 4.2 software and the docking studies were done by Auto dock Tools 1.5.6 and the resource was visualized by discovery studio visualizer. Based on the literature review, purine derivatives were taken from our study to estimate the activity of these derivatives which will be beneficial for the treatment of anticancer. Standard compounds from the literature are collected and QSAR studies have been done. From the QSAR results, new compounds are designed and finally, 15 compounds show the good biological activity of that one compound possess best binding energy with the protein (PDB ID:5FSO). The results are tabulated in Table 4. The CMP_21_M shows a bestdocked activity and good binding energy, further characteristic features are given below [10-13]. This compound may possess good binding energy which will emphasize to design new compounds based on the scaffold. The newly designed compounds are compared with the standard purine analog 6 mercaptopurine and the results show the 
Table 4: Docked compound (5FSO-CMP_21_M Ligand)

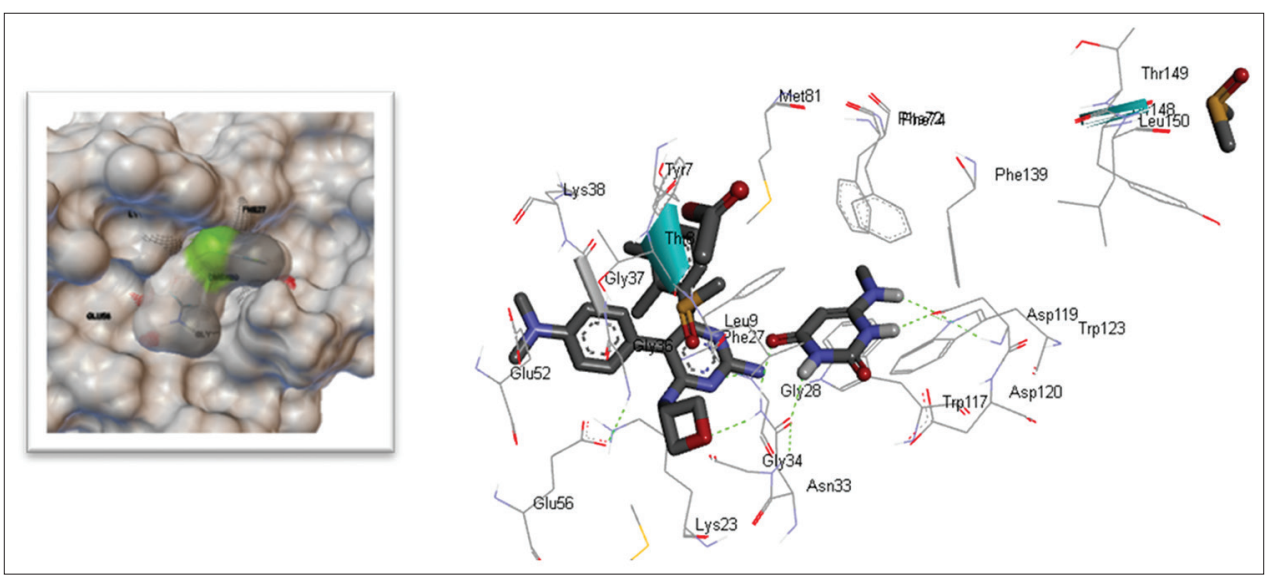

binding energy and dock score are compared and the results depict as the newly designed molecules has better binding energy than standard drug. These compounds may possess better anticancer activity and binding energy of standard purine analog 6-mercaptopurine is -2.93 and the newly designed compound was -13.95 .

The binding DNA modes and the biological effects of DNA with regards to purines and Anthraquinone will have a great role in designing new drugs. These compounds having anticancer application to understand the idea behind designing new targeted drugs [14] and MTH1 used to overcome the incorporation of oxidized nucleotides into the DNA.

\section{ACKNOWLEDGMENT}

The authors are thankful to Vels University (VISTAS) and its management for providing research facilities and encouragement. I take pleasure to express my sincere thanks to Amit Bedi Manager (V Life Sciences Technologies) for his valuable sugges.

\section{REFERENCES}

1. Rosemeyer $\mathrm{H}$. The chemodiversity of purine as a constituent of natural products. Chem Biodivers 2004;1(3):361-401.

2. Dinesh S, Shikha G, Bhavana G, Nidhi S, Dileep S. Biological activities of purine analogs. J Pharm Sci Innov 2012;1(2):29-34.

3. Nissink JW, Bista M, Breed J, Carter N, Embrey K, Read J, et al. MTH1 Substrate Recognition - An Example of Specific Promiscuity. PLoS One 2016;11(3):e0151154.

4. Dutta S, Ray S, Nagarajan K. Docking study of some glutamic acid derivatives as potent antineoplastic agents. Int J Pharm Pharm Sci
2014;6(4):419-22.

5. Lapins M, Prusis P, Staffan UN, Jarl ES. Improved Approach for Proteochemometrics Modeling: Application to Organic Compound - Amine G Protein-Coupled Receptor Interactions. Wikberg Department of Pharmaceutical Biosciences, Uppsala University, Box No. 591 BMC, SE-751 24, Uppsala, Sweden. Available from: http:// wdiva2:169106/FULLTEXT01.pdfww.diva-portal.se/smash/get/. [Last revised on 2005 Sep 20; Last accepted on 2005 Oct 03; Last received on 2005 Jun 23].

6. Dror RO, Jensen MØ, Borhani DW, Shaw DE. Exploring atomic resolution physiology on a femtosecond to millisecond timescale using molecular dynamics simulations. J Gen Physiol 2010;135(6):555-62.

7. Sever M, Podnar T, Runove F, Kordas M. Analog simulation of two clinical conditions: (1) acute left ventricle failure; (2) exercise in patient with aortic stenosis. Comput Biol Med 2007;37(8):1051-62.

8. Silva JR, Rudy Y. Multi-scale electrophysiology modeling: from atom to organ. J Gen Physiol 2010;135(6):575-81.

9. Dror RO, Mildorf TJ, Hilger D, Manglik A, Borhani DW, Arlow DH, et al. Signal transduction. Structural basis for nucleotide exchange in heterotrimeric G proteins. Science 2015;348(6241):1361-5.

10. Sanner MF. Python: A programming language for software integration and development. J Mol Graph Model 1999;17(1):57-61.

11. Sanner MF, Olson AJ, Spehner JC. Reduced surface: An efficient way to compute molecular surfaces. Biopolymers 1996;38(3):305-20.

12. Sanner MF. Python: A programming language for software integration and development. J Mol Graph Model 1999;17(1):57-61.

13. Bajaj C, Pascucci V, Schikore D. Fast IsoContouring for Improved Interactivity, Proceedings of ACM Siggraph/IEEE Symposium on Volume Visualization. San Francisco, CA: ACM Press; 1996. p. 39-46.

14. Adhikari A, Andkamalesh AS. DNA targeted anthraquinone derivatives: An important anticancer agents. Int J Pharm Pharm Sci 2016;8(6):17-25. 